\title{
Ease of Access to An Alternative Food Source Enables Wallabies to Strip Bark in Tasmanian Pinus radiata Plantations
}

\author{
Anna H. Smith ${ }^{1}$, David A. Ratkowsky ${ }^{1}{ }^{\circledR}$, Timothy J. Wardlaw ${ }^{2}$ and Caroline L. Mohammed ${ }^{1, *}$ \\ 1 Tasmanian Institute of Agriculture, University of Tasmania, Private Bag 98, Hobart 7001, Australia; \\ annah_smith@hotmail.com (A.H.S.); d.ratkowsky@utas.edu.au (D.A.R.) \\ 2 ARC Centre for Forest Value, University of Tasmania, Private Bag 55, Hobart 7001, Australia; \\ timothy.wardlaw@utas.edu.au \\ * Correspondence: caroline.mohammed@utas.edu.au
}

Received: 12 February 2020; Accepted: 27 March 2020; Published: 30 March 2020

\begin{abstract}
Bark stripping by the Bennett's wallaby (Macropus rufogriseus (Desmarest) subsp. rufogriseus) from the lower stems of 3-6-year-old radiata pine (Pinus radiata D. Don) causes significant damage in Tasmanian plantations. The usual diet of this generalist herbivore is mainly grasses and broadleaved forbs. As the factors that attract a wallaby to supplement its diet by eating the bark of plantation pine trees are currently not elucidated, the present study aimed to determine how the incidence and severity of bark damage in 12 Tasmanian radiata pine plantations was influenced by various inter-site factors such as the floristic composition of the surrounding forest, and by various intra-site factors such as the height and circumference of individual trees, the number of branches in the first two whorls at the base of the tree, and their internode lengths. It was found that the greater the percentages of bare ground, bracken, and moss present in the five plots at each site, and the greater the percentage of grass, the wallaby's main food source, the greater the likelihood of bark stripping. The difference between the mean minimum soil and air temperatures in spring, a driving force for carbohydrate production that occurs with tree growth in spring or early summer, was the only meteorological observation at the sites that was found to be significantly related to the extent of bark stripping.
\end{abstract}

Keywords: bark stripping; wallabies; supplementary food; radiata pine plantations

\section{Introduction}

Pinus radiata D. Don is a softwood species widely planted worldwide, estimated at over 4 million hectares globally [1], with approximately 770,000 ha growing in southern Australia (including Tasmania). The pests and diseases that currently affect radiata pine plantations can be controlled or tolerated, provided that the plantations are not on sites where the trees are stressed [1]. Less manageable is the damage consisting of bark stripping, girdling or partial girdling by native animals to trees in Australian plantations [2], which may result in the death of the tree. Even when recovery takes place after less severe damage, the tree may become deformed and substantially reduce its value as timber.

In Tasmania, wood quality losses and reduction of potential growth due to bark stripping damage are attributed mainly to the Bennett's wallaby Macropus rufogriseus (Desmarest) subsp. rufogriseus owing to the height of the damage occurring on the tree stems [3]. The only other animal that could cause the damage is the much larger Forester Kangaroo Macropus giganteus Shaw, 1790 subsp. tasmaniensis, but that species is restricted to isolated populations in the midlands and northeastern Tasmania [4], while Bennett's wallaby is found throughout Tasmania [5]. The Brushtail possum Trichosurus vulpecula Kerr, 1792 is usually associated with stripped and broken stems in older, mid-rotation plantations ca. $10-15$ years old [6]. 
Bennett's wallaby is a nocturnal, generalist herbivore with a diet of mainly grasses and broad-leaved forbs [7]. Previous field trials [8] found that browsing of P. radiata seedlings by herbivores was greatest when located in patches of palatable short vegetation such as grass and least in low-quality tall vegetation and shrubs. Nighttime feeding by wallabies is preferred in open grassland and young plantations, while closed canopy environments, such as native forests, are avoided. Daytime sheltering is preferred in older plantations [9].

In 3-6-year-old radiata pine plantations, Bennett's wallabies tear off bark in strips near the base of trees [6]. The stripping exposes the cambium and usually results in extensive resin flow from the damaged section of the stem. When a tree is completely girdled or has had its bark severely stripped, it is at risk of dying. Partially ringbarked trees may survive, but sub-lethal bark stripping wounds may weaken the timber and reduce the wood quality around the location of the damage, resulting in large financial losses [6].

Limitations on food material may promote small mammal attacks on trees, as has been observed in the Northern Hemisphere [10]. The availability of ground cover and the proximity to native vegetation and water are also important, as the mammals tend to harbour in such areas [2]. One overriding factor observed worldwide is that browsed trees are invariably young trees (seedlings or saplings), whether the browsing is done by ungulates as in Europe [11,12], or by marsupials in Australia [13-15].

The social and political pressure to find alternatives to pesticides increased nationally within Australia during the latter part of the 20th Century. Formal health surveillance of state-owned forestry plantations in Tasmania commenced in 1997 using aerial, roadside and ground inspections [16]. Recognizing that a major risk to radiata pine plantations was crop loss and damage due to bark stripping by browsing mammals, the health surveillance program provided an opportunity to identify risk factors associated with the timing and location of severe outbreaks [16]. An earlier study [3] and the current study were undertaken in an endeavour to explore the factors that influence bark stripping by the Bennett's wallaby in Tasmanian pine plantations. In the current study, it was recognised that there are risk factors that operate on more than one spatial scale. Thus, in addition to intra-site factors such as the percentages of the components of vegetation, the number of branches and internode lengths of the trees, and the percentages of tree bark removed, all of which operate at the plot level, there are inter-site factors that are geographical, like the site's altitude, latitude and longitude, or are meteorological, such as rainfall, humidity, and minimum, maximum and average air temperature, that either change very little or cannot readily be measured at the plot level, but do change at the site level. Therefore, it was necessary to try to develop models for the risk factors at the scale of both the plot and the site, bearing in mind that the latter has a much smaller number of experimental units.

\section{Materials and Methods}

\subsection{Study Sites}

Data were collected from twelve Pinus radiata plantations in Tasmania, Australia (Table 1, Figure 1) that were already in commercial production. The sites were selected to represent a range of altitudes, rainfall and damage severity. Plantations were all second rotation, with the trees approximately 3 years old, planted at a spacing of $2 \mathrm{~m}$ between trees and $3 \mathrm{~m}$ between rows with a single application of fertilizer after planting. For the purposes of within-site data collecting, five plots of 20 trees (4 rows $\times 5$ trees) were demarcated on each of the 12 sites, the plot locations being evenly spaced along a central road with approximately $50 \mathrm{~m}$ spacing between plots. The distance into the plantation from the central road was determined randomly using a random number generator. This resulted in an average distance into the plantation of $65 \mathrm{~m}$, ranging from a minimum of $8 \mathrm{~m}$ to a maximum of $182 \mathrm{~m}$ over the 12 plantations. 
Table 1. Attributes of the 12 studied plantations.

\begin{tabular}{|c|c|c|c|c|c|c|c|c|c|}
\hline Site Name & $\begin{array}{l}\text { Lat. } \\
\text { (N) }\end{array}$ & $\begin{array}{l}\text { Long. } \\
\text { (E) }\end{array}$ & $\begin{array}{l}\text { Alt. } \\
\text { (m) }\end{array}$ & $\begin{array}{c}\text { Ave. } \\
\text { Annual } \\
\text { Rainfall (mm) }\end{array}$ & $\begin{array}{l}\text { Ave. Annual } \\
\text { Air } \\
\text { Temp. }\left({ }^{\circ} \mathrm{C}\right)\end{array}$ & $\begin{array}{l}\text { Ave. Min. } \\
\text { Soil Temp. } \\
\text { (Spring) }\left({ }^{\circ} \mathrm{C}\right)\end{array}$ & $\begin{array}{l}\text { Ave. Min. Air } \\
\text { Temp. } \\
\text { (Spring) }\left({ }^{\circ} \mathrm{C}\right)\end{array}$ & $\begin{array}{c}\text { Tdiff } \\
\text { (Ave. Diff. of } \\
\text { Min. Soil and } \\
\text { Air Temps.) }\left({ }^{\circ} \mathrm{C}\right)\end{array}$ & $\begin{array}{c}\text { Average } \\
\text { Damage } \\
\text { Score }(\% \text { girdling) }\end{array}$ \\
\hline $\begin{array}{l}\text { Branchs } \\
\text { Creek }\end{array}$ & -41.27 & 146.66 & 131 & 744 & 12.9 & 9.4 & 8.0 & 1.4 & 0.0 \\
\hline Franklin & -43.06 & 146.88 & 293 & 1123 & 9.7 & 10.9 & 4.7 & 6.2 & 25.5 \\
\hline Inglis River & -41.11 & 145.60 & 111 & 1353 & 11.3 & 8.8 & 6.2 & 2.6 & 22.9 \\
\hline Longhill & -41.34 & 146.49 & 120 & 988 & 11.6 & 7.3 & 6.2 & 1.1 & 2.5 \\
\hline Nicholas 1 & -41.45 & 147.97 & 338 & 915 & 10.6 & 8.1 & 5.1 & 3.0 & 16.1 \\
\hline Nicholas 2 & -41.47 & 147.98 & 324 & 915 & 10.6 & 8.6 & 5.1 & 3.5 & 4.7 \\
\hline Oonah & -41.23 & 145.62 & 454 & 1439 & 11.2 & 7.5 & 6.1 & 1.4 & 0.4 \\
\hline Plenty & -42.87 & 146.89 & 427 & 876 & 9.2 & 8.0 & 4.0 & 4.0 & 16.7 \\
\hline $\begin{array}{l}\text { Springfield } \\
1\end{array}$ & -41.21 & 147.63 & 311 & 785 & 13.0 & 8.4 & 7.3 & 1.1 & 8.7 \\
\hline $\begin{array}{l}\text { Springfield } \\
2\end{array}$ & -41.21 & 147.61 & 294 & 785 & 13.0 & 9.9 & 7.3 & 2.6 & 21.8 \\
\hline Styx & -42.77 & 146.83 & 539 & 714 & 11.6 & 8.0 & 5.6 & 2.4 & 1.3 \\
\hline Tower Hill & -41.53 & 147.91 & 512 & 716 & 11.5 & 6.2 & 5.6 & 0.6 & 41.6 \\
\hline
\end{tabular}

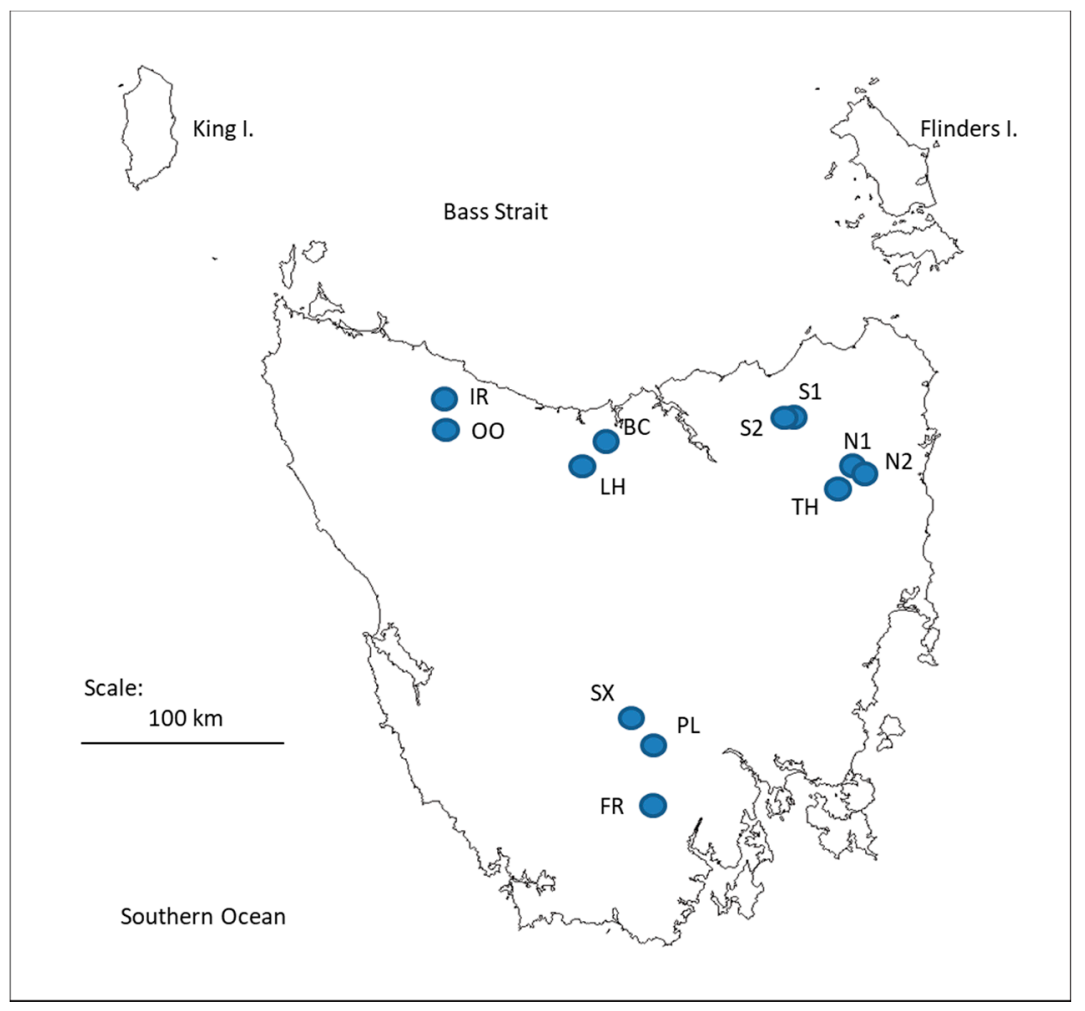

Figure 1. Location of $P$. radiata plantations in Tasmania at which the study was carried out (see Table 1 for latitude, longitude and other site information). BR = Branchs Creek; FR = Franklin; IR = Inglis River LH = Longhill; N1 = Nicholas 1; N2 = Nicholas 2; OO = Oonah; PL = Plenty; S1 = Springfield 1; $\mathrm{S} 2=$ Springfield $2 ; \mathrm{SX}=\mathrm{Styx} ; \mathrm{TH}=$ Tower Hill.

\subsection{Response Variables}

The incidence and severity of bark stripping damage was assessed at each site between October 2006 and January 2007 to quantify damage that had occurred in the preceding winter and spring. In addition to scoring the incidence (presence or absence) of old and fresh damage, the area damaged $\left(\mathrm{cm}^{2}\right)$ was also determined by measuring the length and width of each bark stripping event. An overall percentage girdling score was derived as an estimate of the percentage of the stem circumference that had its bark removed. 


\subsection{Explanatory Variables}

Variables with the potential for explaining the observed percentage girdling fall into several categories: those which potentially aided access; those potentially hindering access; those potentially providing a food source; and climate attributes that may affect plant chemistry. Components of ground cover and projected plant cover were measured using ocular estimates of percent cover in each of the three randomly located $1 \mathrm{~m}^{2}$ quadrats along a diagonal transect within each plot.

The variables (measured as a percentage cover) that potentially aided access were (Table 2) bare ground, Austral bracken (Pteridium esculentum), grass and moss/liverworts. The variables that may hinder the movement of a wallaby across a plot were (Table 2) the percentage covered by woody debris and the percentage covered by rock. Several tree-level attributes that potentially aided or hindered the access of wallabies were also measured. They included: tree height (measured using a height pole) and circumference at $20 \mathrm{~cm}$ above ground level (measured using a diameter tape); the number of branches in the first and second whorls (i.e., the more branches, the lesser the ease of access); and, the length of the internodes between whorls (i.e., the shorter the length, the lesser the ease of access).

The potential food source category of explanatory variables included two groups of plant species: the percentage of plot area covered by grasses, which has a double role as they also aid access to the site; and, the combined percentage of grasses, herbs and forbs. The percent plot cover of wildling (i.e., unplanted) Pinus radiata was also included in the category of potential food sources. Other vegetative variables, which are probably not food sources, such as Acaena novae-zelandiae, Acacia dealbata, Gonocarpus teucrioides, species of Juncus, Ozothamnus ferrugineus and Pomaderris apetala, were also measured and considered as potential explanatory variables. For brevity, not all the potential food sources are listed in Table 2.

A further set of potential explanatory variables involved climate data. Interpolated estimates (data drill) of various aspects of rainfall and temperature data were downloaded from SILO (an enhanced climate data bank [17]). These included average annual minimum and maximum temperature, average minimum and maximum temperature in each of the four seasons, as well as average annual rainfall, average radiation, average vapour pressure and average annual evaporation. The only climate variable actually measured on-site was the soil temperature, which was recorded continuously between March-December, 2007 at 2-hourly intervals using a Thermochron iButton (Dallas Communications, Texas) buried at a depth of $15 \mathrm{~cm}$ in the centre of each plot. It has been reported that environmental stress in plants is associated with an increase in the conversion of starches to sugars [18,19]. That is, while increasing air temperature triggers shoot activity, low soil temperature and therefore low root activity means that the demand for nutrients and/or water exceeds their supply, potentially causing stress. It is hypothesized that the most attractive time for bark stripping by wallabies may be when soluble sugars and starch begin their flow in the phloem tissue of a tree. To test this, differences were calculated between the recorded soil temperature and the daily air temperatures obtained from the data drill in springtime. Thus, the derived temperature difference Tdiff (see Table 1), the difference between the minimum daily soil and air temperatures in spring, is an explanatory variable of interest. Under the hypothesis, the larger the value of Tdiff, the greater would be the expected extent of bark girdling. 
Table 2. Description, abbreviations and units of the main variables measured in three transects in five plots at each of the 12 sites in Tasmanian Pinus radiata plantations and used in the statistical analysis. Plot-specific and site-specific variables are shown separately. For brevity, individual species of vegetation that may provide a food source for wallabies, although they were measured, are not shown.

\begin{tabular}{llc}
\hline \multicolumn{1}{c}{ Variable } & \multicolumn{1}{c}{ Description } & Units \\
\hline $\begin{array}{l}\text { Plot-specific: } \\
\text { \%Gird }\end{array}$ & Cumulative damage score, percentage of bark removed & \\
ang\%Gird & Angular transformation of cumulative damage score \%Gird & $\%$ \\
BareGrd & Percentage of area as bare ground & $\%$ \\
BBM & Composite variable, = BareGrd+Bracken+Moss & $\%$ \\
BBMG & Composite variable, = BareGrd+Bracken+Moss+Grass & $\%$ \\
Bracken & Percentage of area as Pteridium esculentum & $\%$ \\
Grass & Percentage of area as grass & $\%$ \\
height & Average height of the trees in the plot & $\mathrm{m}$ \\
inter_1 & Length of first internode of tree & $\mathrm{mm}$ \\
inter_2 & Length of second internode of tree & $\mathrm{mm}$ \\
LiveMat & Percentage of area as live material (grasses, herbs, forbs, etc.) & $\%$ \\
Moss & Percentage of area as mosses and liverworts & $\%$ \\
P_radiata & Percentage of area containing wilding Pinus radiata & $\%$ \\
Rock & Percentage of area occupied by rock & $\%$ \\
RockWood & Composite variable, = Rock+WoodDeb & $\%$ \\
SoilTmin & Minimum soil temperature in spring months, iButton & $\%$ \\
whorl_1 & No. of branches in first whorl of tree & ${ }^{\circ} \mathrm{C}$ \\
whorl_2 & No. of branches in second whorl of tree & integer \\
WoodDeb & Percentage of area as woody debris & integer \\
Site-specific: & & $\%$ \\
Tdiff & Difference between mean minimum soil and air temperatures & $\%$ \\
& in spring months, = SoilTmin-TminSpr & ${ }^{\circ} \mathrm{C}$ \\
TminSpr & Minimum air temperature in spring months (SILO) & \\
\hline
\end{tabular}

\subsection{Statistical Analysis}

Stepwise multiple regression analysis was carried out on the mean values of all explanatory and response variables using PROC REG of SAS (Vers. 9.4, SAS Institute, Cary, NC, USA.). For data at the plot level, there were 60 sampling units, made up of five plots at each of the 12 sites. These stepwise regressions utilized the plot-specific variables listed in Table 2, excluding meteorological variables from SILO, such as minimum and maximum air temperatures at various seasons, which apply at a site level rather than a plot level. To make use of the site-specific meteorological information, further stepwise regressions were carried out on site averages, obtained for each variable by averaging the data in 15 transects (i.e., three transects in each of five plots). This restricted the data set to only 12 sampling units, but allowed regression analysis to be applied at the larger spatial scale. For both sets of regressions, the response variable was percentage girdling (\%Gird), which was transformed using the angular transformation, ang\%Gird $=\sin ^{-1}$ (sqrt(\%Gird)), this transformation producing a set of residuals which was closer to being normally distributed than \%Gird itself or a logarithmic transformation of \%Gird. The potential explanatory variables used for the regression analysis are tabulated in Table 2. To decide upon the best of several competing models, the Akaike Information Criterion (AIC) and Bayesian Information Criterion (BIC) were used as the main indicators [20]. In addition, the proportion of explained variation $\left(R^{2}\right)$ and adjusted proportion of explained variation $\left(\right.$ adj $\left.R^{2}\right)$ were also calculated and contrasted with AIC and BIC. In addition to stepwise regressions, the technique 'all possible regressions' involving a given number of explanatory variables, was also employed with the objective being to obtain models with the lowest possible values of AIC and BIC. 


\section{Results}

\subsection{Percentage Girdling at the Plot Level $(n=60)$}

The best regression relationships, irrespective of whether the decision was based upon AIC, BIC or adj $R^{2}$, were obtained when bare ground, bracken and moss were all included in the model, there being little difference between including these explanatory variables separately or as their sum in the composite variable BBM (Table 3). AIC chose the model in which bare ground, bracken and moss appear separately, but BIC, which incorporates a penalty for extra model terms and thereby favours models with a smaller number of terms, chose the model with the composite variable BBM. Bare ground, bracken and moss are all associated with access, with large values of each indicating greater ease of access. No potential explanatory variable for percentage girdling related to a source of food, such as grass, herbs and forbs, whether alone or summed together, correlated with percentage girdling nor were they significant in any other multiple regression model in which they were tried. Other vegetative components, such as internode length and the number of branches in the lowest two internodes, were also non-significant contributors to the explained variation in girdling damage at the plot level.

Table 3. Best plot-level regression relationships for the angular transformation of percentage girdling (ang\%Gird). Number of sampling units $=60$ (i.e., 5 plots at each of 12 sites).

\begin{tabular}{|c|c|c|c|}
\hline Regression Relationship & AIC & BIC & $\operatorname{adj} R^{2}$ \\
\hline ang $\%$ Gird $=0.106+0.00326($ BareGrd $)+0.0136($ Bracken $)+0.00947($ Moss $)$ & -187.9 & -185.4 & 0.282 \\
\hline ang $\%$ Gird $=0.09743+0.00500(B B M)$ & -187.8 & -185.6 & 0.257 \\
\hline
\end{tabular}

\subsection{Percentage Girdling at the Site Level $(n=12)$}

As was the case with the results at the plot level, the composite variable BBM, being the sum of the percentages of bare ground, bracken and moss, was positively correlated with the transformed percentage girdling (ang\%Gird) in the best model (Table 4). Included also was the term Grass, representing the area occupied by grass, a wallaby's main food source. The third and final term in the best model involves Tdiff, the mean difference between the minimum daily soil and air temperatures in the spring season, with a positive coefficient that supports the hypothesis that the trees are more attractive in spring. Figure 2 provides a graphical representation of the four components of ease of access for wallaby browsing, viz. bare ground, bracken, moss and grass (which is a component of ease of access as well as a food source). Sites on the right-hand side of Figure 2 (i.e., the ones with high percentage girdling) almost always have greater amounts of at least some of these variables than the sites with low percentage girdling (those on the left-hand side of Figure 2).

Table 4. Best site-level regression relationship for the angular transformation of percentage girdling (ang\%Gird) as adjudged by the BIC. Number of sampling units $=12$, one per site, derived by averaging over the 15 transects ( 3 transects in each of the 5 plots) in each of the 12 sites.

\begin{tabular}{lccc}
\hline & AIC & BIC & adj $R^{2}$ \\
\hline Model: ang\%Gird $=-0.6288+0.01493(\mathrm{BBM})+0.01034($ Grass $)+0.06646$ (Tdiff) & -55.14 & -49.64 & 0.834 \\
\hline
\end{tabular}

Notes: AIC = Akaike's Information Criterion, BIC $=$ Bayesian Information Criterion and adj $R^{2}=$ the adjusted $\mathrm{R}^{2}$, i.e., the proportion of explained variation based upon the variance. The explanatory variables are BBM (= the sum of the percentages of area of bare ground, bracken and moss), Grass (the percentage of area as grass) and Tdiff (= the difference between mean minimum soil and air temperatures in the spring months). 
No other potential explanatory variables associated with ease or difficulty of access, or vegetative components, were serious contenders as predictors of percentage girdling at the site level $(n=12)$. These included variables that were expected to affect access (the number of branches in the first and second whorls of the tree, the length of the first and second internodes, the average height and average circumference of the tree). Of these six variables, only the pairwise correlation coefficient of whorl_1 with ang\%Gird achieved statistical significance $(r=0.654, p=0.021)$, but the regression coefficient was positive, not the expected negative value if a larger number of branches in the first whorl was inhibitory to wallaby attack.

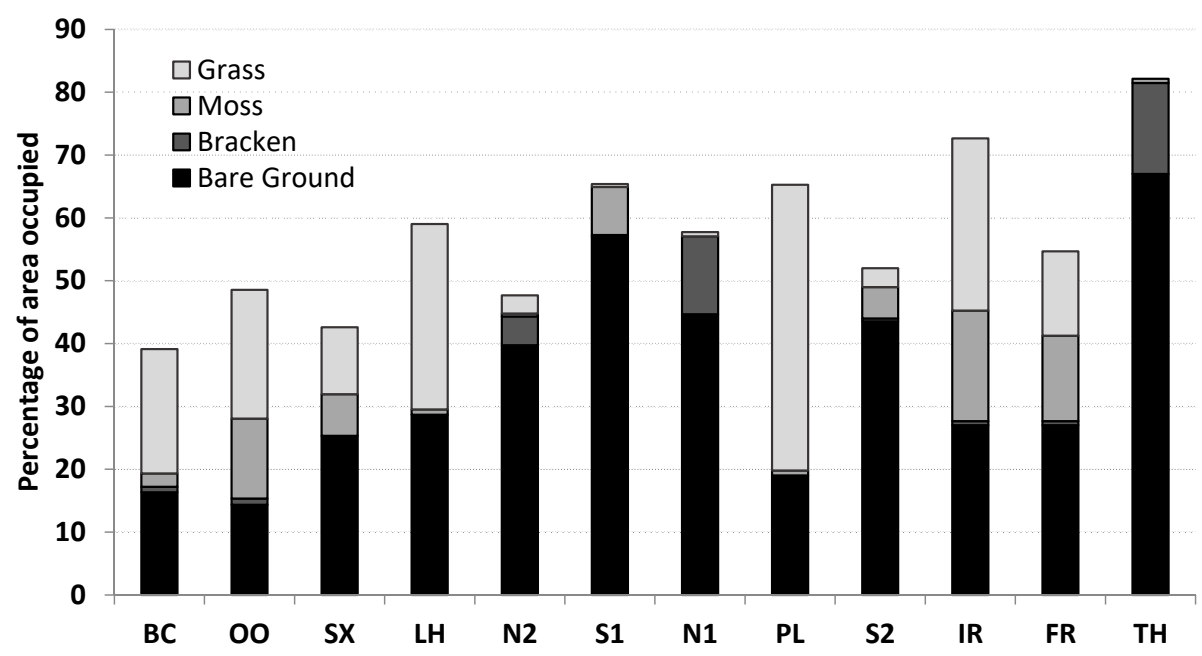

Figure 2. The stacked bar graph depicts four of the components of the vegetation. The total height of each bar corresponds to BBMG, the sum of the percentages of the area occupied by bare ground, bracken, moss and grass. The horizontal axis lists the 12 sites from left to right in order of increasing percentage girdling. $\mathrm{BC}=$ Branchs Creek, $0 \%$ girdling; $\mathrm{OO}=$ Oonah, $0.4 \% ; \mathrm{SX}=$ Styx, $1.3 \%$; LH = Longhill, 2.5\%; N2 = Nicholas 2, 4.7\%; S1 = Springfield, 8.7\%; N1 = Nicholas 1, 16.1\%; PL = Plenty, 16.7\%; S2 = Springfield 2, 21.8\%; IR = Inglis River, 22.9\%; FR = Franklin, 25.5\%; TH = Tower Hill, 41.6\%.

\section{Discussion}

The statistically significant regression relationships given in Tables 3 and 4 indicate that bark stripping of plantation radiata pine may be determined principally by the ease to which Bennett's wallabies have access to the trees. The most significant variables in the regression equations were bare ground, bracken and moss, which appear in the most significant models either individually or collectively in the composite variable BBM. Although bracken in Tasmania can grow densely, forming extensive patches in areas which have been recently cleared or subject to severe disturbance, their pliable stems offer little resistance to the movement of animals the size of a wallaby and have the added advantage of providing them with shelter and cover. The extent of bare ground, bracken and moss varied greatly at the 12 sites of this study, as did the frequencies of occurrence of the various other components of the vegetation. For example, the site with the greatest percentage girdling, Tower Hill, had the greatest amount of bare ground (67\%) but the least amount of grass $(0 \%)$, whereas a site with a moderate percentage girdling, Plenty, had the most grass (45.5\%) and the third least amount of bare ground (19\%). Therefore, no single variable can be identified as being the most important for providing a wallaby easy access to the trees. The stacked bar graph given by Figure 2 reveals that bracken occurred in a substantial amount at only three of the sites (Nicholas 1, Nicholas 2 and Tower Hill), being present at $1 \%$ or less and barely visible on the scale of Figure 2 at the other nine sites. Similarly, the distribution of moss was very spotty, although present at all but one of the sites; it had an almost zero pairwise correlation with percentage girdling, despite its importance as an explanatory variable in the models in Tables 3 and 4. This illustrates the dangers of accepting a multiple linear regression 
model at face value, without closer examination. The three sites that had substantial bracken had, in contrast, very little moss (Figure 2). Furthermore, no site was simultaneously abundant in all three of the components bare ground, bracken and moss, which could explain why the composite variable BBM may be a better explanatory variable for correlating with percentage girdling than any of its separate components. As there are only 12 sites, one spurious or atypical data point can have a strong influence on which variables appear in the best predictive model. In Figure 2, the sites are arranged from left to right in order of increasing percentage girdling. If ease of access to the site were the full story, then the height of the bars in Figure 2 (BBMG) would tend to rise in tandem with increased percentage girdling. Although generally true, this is not entirely the case, as Longhill, Springfield 2 and Franklin deviate from the expected trend.

Further attempts were made at finding components of the vegetation that correlate with percentage girdling. Some of the components, e.g., Ozothamnus ferrugineus and wildling P. radiata, the latter found to be attractive to browsing mammals such as wallabies and possums, and targeted in preference to crop trees [3], were abundant at only one of the sites and were absent or sparsely represented elsewhere. A consequence of this is that a high contribution of one of those components to the overall explained variation is likely to be spurious. Other site factors that were investigated for a possible link to percentage bark stripping damage include the number of whorls on the stem of the $P$. radiata tree and the distance between internodes. Although ang\%Gird correlated significantly $(\mathrm{P}<0.05)$ with the average number of branches in the first whorl of the tree, the positive correlation obtained defies explanation, as the prevailing belief was that the more branches in a whorl, the more difficult it should be for a wallaby to gain access to the tree.

Bark stripping of Scots pine and lodgepole pine by moose in Sweden [21] is at its most intense in winter when alternative food resources are generally limiting. Seasonal changes in the carbohydrate physiology of the trees may contribute to when trees are the most susceptible to browsing damage. In Tasmania, browsing pressure on highly palatable forage species increased in winter and spring, when soluble sugars were also at a seasonal peak [22]. Sugar levels increase in the bark and foliage of some pine species throughout autumn as part of the hardening process [23]. For example, both soluble sugar and shoot nitrogen concentrations increased in $P$. halapensis seedlings as minimum temperatures dropped below $9{ }^{\circ} \mathrm{C}$ [24]. Larger reserves of sugars are known to be associated with increased cold tolerance in lodgepole pine (P. contorta) and Scots pine (P. sylvestris) [25-27].

Previously held views on what promotes bark stripping damage due to browsing mammals in Tasmanian pine plantations are generally not supported by the results of the present survey. For example, although bark stripping in plantation P. radiata due to Bennett's wallaby was previously found to be significantly greater $(p=0.002)$ at high elevation sites [3], we found no hint of an association, with both high and low bark damage occurring at sites of all elevations. The same was the case for rainfall; whereas the earlier study found significantly greater $(p<0.001)$ bark stripping damage at wetter sites [3], no association was found in the present study. One should also keep in mind that the apparent low P-values previously reported [3] were not supported by high values of the proportion of explained variation in bark stripping incidence, those being $R^{2}=0.04$ for elevation and $R^{2}=0.10$ for rainfall. The significant associations are due to the large sample sizes ( $n=229$ forest blocks) rather than due to strong relationships. Therefore, it would be unrealistic to expect a definitive result to be obtained from the present study, which had only 60 plots at the plot level occurring at 12 sites. Other potential factors such as aspect and slope of the sites, underlying geology, and proximity to, and vegetative composition of, nearby forests have little likelihood of being found to influence bark stripping damage, especially as the "levels" of these factors have highly unequal sample sizes, reducing the power of any statistical test.

A study in two large 4-5-year-old Pinus radiata plantations near Tarraleah in central-western Tasmania [22], far from any of the 12 plantations in the present study, found that the bark of $P$. radiata had a high average annual sugar concentration, and a low average annual starch concentration, as did the two exotic grasses Poa annua and Holcus lanatus, both of which were heavily grazed by Bennett's 
wallaby, grasses being the main dietary component of the species [7]. This suggests that non-preferred food sources, such as bark in small quantities, form part of a mixed diet, which may have positive effects on nutrition and digestion, as is the case for foraging bark-stripping mammals in other parts of the world, e.g., moose in Scandinavia [28].

\section{Conclusions}

The main conclusion to be drawn from the results of the present study is that a combination of four components to the vegetation, viz. bare ground, bracken, moss and grass, plays a major role in assisting access to Tasmanian pine plantations by wallabies. However, the details of how the mechanism operates and how the components interact is not straightforward and is unlikely to be readily elucidated by small-scale surveys. In addition, it appears that a site can change its susceptibility to bark stripping with time. For example, in an earlier study [3], Oonah was one of the most severely affected sites, with a mean bark stripping of $47.3 \%$ compared to less than $1 \%$ in the present study. Therefore, chance is likely to play a role at any specific site and vary from year to year, increasing the difficulty of the task of unravelling the factors that are responsible for enticing wallabies to strip bark from $P$. radiata trees in Tasmanian plantations.

Author Contributions: A.H.S., T.J.W. and C.L.M. designed the experiment; A.H.S. carried out the field work; D.A.R. analysed the data. All authors have read and agreed to the published version of the manuscript.

Funding: This research received funding from the Australian Research Council, Forestry Tasmania, Hosking Forestry Ltd. and Taswood Growers, administered by a University of Tasmania Linkage Project (LP669742).

Acknowledgments: We thank David Page for his extensive help with sampling.

Conflicts of Interest: The authors declare no conflict of interest.

\section{References}

1. Mead, D.J. Sustainable Management of Pinus radiata Plantations; FAO Forestry Paper No. 170; FAO: Rome, Italy, 2013.

2. McNally, J. Damage to Victorian exotic pine plantations by native animals. Aust. For. 1955, 19, 87-99. [CrossRef]

3. Wotherspoon, K. An Analysis of the Factors Influencing Bark Stripping by Browsing Mammals in Pinus radiata Plantations; Division of Forestry Research and Development, Forestry Tasmania: Hobart, Australia, 2004; p. 28, unpublished confidential client report.

4. Department of Primary Industries, Parks, Water and the Environment, Tasmanian Government. 2014. Available online: http://dpipwe.tas.gov.au/wildlife-management/living-with-wildlife/living-with-kangaroosand-wallabies (accessed on 26 May 2017).

5. Calaby, J.H. Marsupials. In The Complete Book of Australian Mammals; Strahan, R., Ed.; Angus \& Robertson: Sydney, Australia, 1983; pp. 239-241.

6. Wardlaw, T. A Manual of Health Problems Affecting Pinus radiata in Tasmania; Technical Report 12/2003; Forestry Tasmania, Division of Forest Research and Development: Hobart, Australia, 2003.

7. Sprent, J.; McArthur, C. Diet and diet selection of two species in the macropodid browser-grazer continuum—Do they eat what they 'should'? Aust. J. Zool. 2002, 50, 183-192. [CrossRef]

8. Pietrzykowski, E.; McArthur, C.; Fitzgerald, H.; Goodwin, A.N. Influence of patch characteristics on browsing of tree seedlings by mammalian herbivores. J. Appl. Ecol. 2003, 40, 458-469. [CrossRef]

9. Le Mar, K.; McArthur, C. Comparison of habitat selection by two sympatric macropods, Thylogale billardierii and Macropus rufogriseus, in a patchy eucalypt-forestry environment. Austral Ecol. 2005, 30, 674-683. [CrossRef]

10. Gill, R.M.A. A review of damage by mammals in North Temperate Forests: 2. Small mammals. Forestry 1992, 65, 281-308. [CrossRef]

11. Díaz-Yáñez, O.; Mola-Yudego, B.; González-Olabarria, J.R. What variables make a forest stand vulnerable to browsing damage occurrence? Silva Fenn. 2017, 51. [CrossRef] 
12. Senn, J.; Suter, W. Ungulate browsing on silver fir (Abies alba) in the Swiss Alps: Beliefs in search of supporting data. For. Ecol. Manage. 2003, 181, 151-164. [CrossRef]

13. Di Stephano, J. Mammalian browsing damage in the Mt. Cole State forest, southeastern Australia: Analysis of browsing patterns, spatial relationships and browse selection. New For. 2005, 29, 43-61. [CrossRef]

14. Hazeltine, A.; Kirkpatrick, J.B. Practical and theoretical implications of a browsing cascade in Tasmanian forest and woodland. Aust. J. Bot. 2015, 63, 435-443. [CrossRef]

15. Stutz, R.S.; Banks, R.B.; Dexter, N.; McArthur, C. Herbivore search behaviour drives associational plant refuge. Acta Oecol. 2015, 67, 1-7. [CrossRef]

16. Wardlaw, T. The evolution of forest health surveillance in Tasmania. Tasforests 2008, 17, 57-66.

17. Queensland Government. SILO Climate Data. Department of Science, Information Technology, Innovation and the Arts, The State of Queensland, Australia. Available online: http://www.longpaddock.qld.gov.au/ (accessed on 2 January 2014).

18. Kobe, R.K. Carbohydrate allocation to storage as a basis of interspecific variation in sapling survivorship and growth. Oikos 1997, 80, 226-233. [CrossRef]

19. Kaelke, C.M.; Dawson, J.O. The accretion of nonstructural carbohydrates changes seasonally in Alnus incana ssp. rugosa in accord with tissue type, growth, N allocation, and root hypoxia. Symbiosis 2005, 39, 61-66.

20. Burnham, K.P.; Anderson, D.R. Multimodel inference: Understanding AIC and BIC in model selection. Sociol. Methods Res. 2004, 33, 261-304. [CrossRef]

21. Ball, J.P.; Dahlgren, J. Browsing damage on pine (Pinus sylvestris and Pinus contorta) by a migrating moose (Alces alces) population in winter: Relation to habitat composition and road barriers. Scand. J. For. Res. 2002, 17, 427-435. [CrossRef]

22. Page, D.E.; Close, D.; Beadle, C.L.; Wardlaw, T.J.; Mohammed, C.L. Seasonal dynamics in understorey abundance and carbohydrate concentration in relation to browsing and bark stripping of Tasmanian Pinus radiata plantations. For. Ecol. Manage. 2013, 296, 98-107. [CrossRef]

23. Levitt, J. Response of Plants to Environmental Stresses. Volume I. Chilling, Freezing and High Temperature Stresses; Academic Press: New York, NY, USA, 1980; 497p.

24. Fernández, M.; Royo, A.; Gil, L.; Pardos, J.A. Effects of temperature on growth and stress hardening development of phytotron-grown seedlings of Aleppo pine (Pinus halepensis Mill.). Ann. For. Sci. 2003, 60, 277-284. [CrossRef]

25. Ögren, E. Effects of climatic warming on cold hardiness of some northern woody plants assessed from simulation experiments. Physiol. Plant. 2001, 112, 71-77. [CrossRef] [PubMed]

26. Ögren, E.; Nilsson, T.; Sundblad, L.G. Relationship between respiratory depletion of sugars and loss of cold hardiness in coniferous seedlings over-wintering at raised temperatures: Indications of different sensitivities of spruce and pine. Plant Cell Environ. 1997, 20, 247-253. [CrossRef]

27. Repo, T.; Leinonen, I.; Ryyppö, A.; Finér, L. The effect of soil temperature on the bud phenology, chlorophyll fluorescence, carbohydrate content and cold hardiness of Norway spruce seedlings. Physiol. Plant. 2004, 121, 93-100. [CrossRef] [PubMed]

28. Milligan, H.T.; Koricheva, J. Effects of tree species richness and composition on moose winter browsing damage and foraging selectivity: An experimental study. J. Anim. Ecol. 2013, 82, 739-748. [CrossRef] [PubMed]

(C) 2020 by the authors. Licensee MDPI, Basel, Switzerland. This article is an open access article distributed under the terms and conditions of the Creative Commons Attribution (CC BY) license (http://creativecommons.org/licenses/by/4.0/). 